\title{
APPENDIX 2A: VARIANT READINGS
}

\section{Based on Collations by Morgan Reed}

The following table gives the variants of Mosul against Leiden. The fourth column indicates the support for the Mosul reading as follows:
early
first millennium up to and including the tenth century.
late post tenth century (making use of the Leiden apparatus).
Lee Lee's edition (1823) agrees with Mosul.
Urmia the Urmia edition (1852) agrees with Mosul. no support Mosul's reading is unique.

\section{Place}

1 Chronicles

$1: 38$

$1: 43$

$1: 46$

1:46

$1: 50$

1:50

$2: 2$

$2: 26$

2:29

$$
\text { حتن احنap }
$$

Mosul

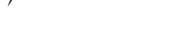

محقة

حقهم

حقهد

حم

ل

ona

لإ,oمتا

and

doano

حil

90000

محسمي

ajon

Loa La

$-90$

مaمة
Leiden/7a1

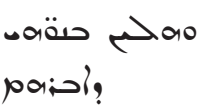

حقوص

محقة حس

محقة -0.

ومبحم

ومهخ

مan

لمب,منتا

ons

onم

ح

!

a:per

o

-9

baco
Ms support

for Mosul

Lee, Urmia

early

Lee, Urmia

late

late

early

early

late

early

early

Lee

early

Lee, Urmia

early

late

early 


\begin{tabular}{|c|c|c|c|}
\hline Place & Mosul & Leiden/7a1 & $\begin{array}{l}\text { Ms support } \\
\text { for Mosul }\end{array}$ \\
\hline $2: 34$ & UR & IN & early \\
\hline $2: 51$ & ححى & حـ & Urmia \\
\hline $3: 1$ & بو & م & Urmia \\
\hline $3: 1$ & ب) & م & Lee, Urmia \\
\hline 3:8 (L 3:7) & io & om & early \\
\hline $3: 17$ & محقةص & مح:a & Lee, Urmia \\
\hline $3: 20$ & مسمحرا & مسمحا & Lee, Urmia \\
\hline $4: 9$ & 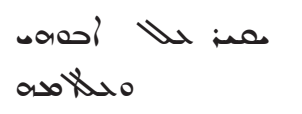 & 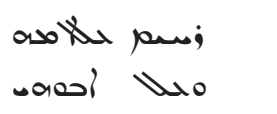 & Lee, Urmia \\
\hline $4: 15$ (L 4:12) & 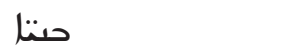 & حقوص & late \\
\hline 4:15 (L 4:12) & ومحد ح: مهار & بهد & early \\
\hline $4: 15$ & "محقهم وملح & محتهوس بحلح حن: & early \\
\hline $4: 15$ & aمر حid & ممار وحزه & early \\
\hline $4: 27$ & pala & alda & Lee, Urmia \\
\hline $4: 28$ & 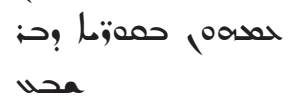 & حح: محس & Lee, Urmia \\
\hline $4: 32$ & 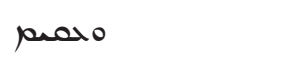 & حمبر & early \\
\hline $4: 38$ & 0حصـ & סححـ & late \\
\hline $4: 39$ & حمب:سه & خمبسسه & $\begin{array}{l}\text { 7a1, Lee, } \\
\text { Urmia }\end{array}$ \\
\hline $4: 41$ & סأمنحه & من:ح & early \\
\hline 4:41 & 2 & के & early \\
\hline $5: 1$ & INoal aofo & ancal ij, & Lee, Urmia \\
\hline $5: 7$ & 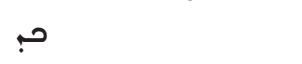 & 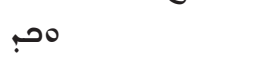 & early \\
\hline $5: 9$ & محبما حمبستشة & محمبسسة & late \\
\hline $5: 11$ & وممحا •وملحا & بمحار & early \\
\hline $5: 18$ & متهل مهص:| & no seyāme & early \\
\hline $5: 21$ & م مسسا & seyāme & early \\
\hline $5: 23$ & مب:مار & مبا & late \\
\hline $5: 23$ & حومدا :وزها & حومى لo & Lee, Urmia \\
\hline $5: 24$ & مa & م00 & late \\
\hline \multicolumn{4}{|c|}{$\begin{array}{l}\text { 6:1-15 in Mosul, Lee, Urmia }=\mathrm{L} \\
5: 27-41\end{array}$} \\
\hline 6:17 (L 6:2) & ?حتس 》ـمعן & ?حقةa ? & early \\
\hline 6:21 (L 6:6) & أوه ح:a & أوه ح:ه וوس ح:ه & Lee, Urmia \\
\hline
\end{tabular}




\begin{tabular}{|c|c|c|c|}
\hline Place & Mosul & Leiden/7a1 & $\begin{array}{l}\text { Ms support } \\
\text { for Mosul }\end{array}$ \\
\hline 6:22 (L 6:7) & & أمی: & Urmia \\
\hline 6:30 (L 6:15) & aمسا حزa & ممسا حزه مسل & Lee, Urmia \\
\hline 6:32 (L 6:17) & مه:ما & ممصرا & early \\
\hline 6:33 (L 6:18) & منحى| & seyāme & early \\
\hline 6:39 (L 6:24) & 9oi? & i & early \\
\hline 6:49 (L 6:34) & גلط مب:حسا & ممفنحم גط" & Lee, Urmia \\
\hline 6:50 (L 6:35) & ممنحم حلحة: الحمر; حنه & الحسر; حبه حسا وحسة|l & Lee, Urmia \\
\hline 6:54 (L 6:39) & مه & مهار & no support \\
\hline 6:55 (L 6:40) & مح:0م & حص:0 & Lee, Urmia \\
\hline 6:55 (L 6:40) & محدדa & 0حمد001 & early \\
\hline 6:56 (L 6:41) & ومنــ/ موبوتهة & ومهزما وبم:تهة & early \\
\hline 6:57 (L 6:43) & مالخسم & after nosillo & late \\
\hline & 0حمو:0سة & 0حصف:0سة & \\
\hline 6:60 (L 6:45) & م & م) & late \\
\hline 6:61 (L 6:46) & مب محهر & مي محها ومنحه| & Urmia \\
\hline 6:63 (L 6:48) & ? & & late \\
\hline 6:65 (L 6:50) & Daso & مسهح حهما & early \\
\hline 6:71 (L 6:56) & oححة.0ص & لحقةهـ & late \\
\hline 6:77 (L 6:62) & م & 200 & late \\
\hline $7: 2$ & تمس & a) & Lee, Urmia \\
\hline $7: 2$ & حم & הa & late \\
\hline $7: 2$ & حod & ححب:0alo & early \\
\hline $7: 4$ & jog & क्व & Lee, Urmia \\
\hline $7: 10$ & مa & مي0 & Lee, Urmia \\
\hline $7: 11$ & a: & 入: ل:a & early \\
\hline $7: 11$ & أحة|aloa & احمة pala & Urmia \\
\hline & & حمتحه001 & \\
\hline $7: 11$ & حم:حر & ومنحا & early \\
\hline $7: 15$ & لمح & تصح لهa & early \\
\hline $7: 15$ & gisng & asug! & early \\
\hline $7: 16$ & مخبL & محبL حه & early \\
\hline $7: 23$ & ححمه & ححشهة & Lee, Urmia \\
\hline 7:29 & Wh & Who & late \\
\hline
\end{tabular}




\begin{tabular}{|c|c|c|c|}
\hline Place & Mosul & Leiden/7a1 & $\begin{array}{l}\text { Ms support } \\
\text { for Mosul }\end{array}$ \\
\hline $7: 29$ & 00 & סעلים & late \\
\hline $7: 33$ & مa & & late \\
\hline 7:35 (L 7:40) & aحم حقם , بأمن: & aحم مخدا حتص & late \\
\hline $8: 2$ & oilom & ل ملمس & early \\
\hline $8: 6$ & حمث & هم & late \\
\hline $8: 12$ & oọ & 000 & Urmia \\
\hline $8: 25$ & محتس & حتس & late \\
\hline $8: 32$ & 98 & 9ी & early \\
\hline $8: 38$ & $a$ & om & no support \\
\hline $8: 39$ & الحفحه & ioامه> & early \\
\hline $8: 40$ & حتا وiحهر & حقaم- 9iolp & Lee, Urmia \\
\hline 8:40 & حته0 & محتب100ر & Lee, Urmia \\
\hline $9: 1$ & sog & एक्ष & Lee, Urmia \\
\hline $9: 3$ & 1,000 & حتس مدوبا & early \\
\hline $9: 5$ & 20 & م & early \\
\hline $9: 5$ & ومسهرا & seyāme & late \\
\hline 9:18 & مهرill & seyāme & Lee, Urmia \\
\hline $9: 19$ & مص:م| & seyāme & early \\
\hline 9:19 & موميا ممسلا & seyāme & late \\
\hline $9: 22$ & بحب0 & وحص: & Lee, Urmia \\
\hline $9: 26$ & مسمى 0له 009 & مسمى 000 oهile & Lee, Urmia \\
\hline $9: 26$ & مسمى2 & مخحتها & Lee, Urmia \\
\hline $9: 27$ & 范 & no seyāme & early \\
\hline $9: 30$ & مهمب & مهقس & early \\
\hline $9: 31$ & log exa & loo ex ad & Lee, Urmia \\
\hline $9: 32$ & Lo:a & om & early \\
\hline $9: 44$ & wario & Hoal & Urmia \\
\hline $10: 3$ & محب مبرا & مح برا أهم & late \\
\hline 10:6 & סמי & م- & early \\
\hline $10: 8$ & olio & oli & early \\
\hline $10: 9$ & 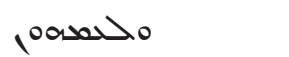 & 0حمد00, & early \\
\hline $11: 2$ & Ni & or Ni & early \\
\hline $11: 3$ & متر وحت مهن:ط & 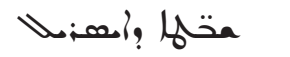 & Lee, Urmia \\
\hline $11: 3$ & حمعهـ| & | & early \\
\hline 11:5 & & 3متج & early \\
\hline
\end{tabular}




\begin{tabular}{|c|c|c|c|}
\hline Place & Mosul & Leiden/7a1 & $\begin{array}{l}\text { Ms support } \\
\text { for Mosul }\end{array}$ \\
\hline 11:8 & وحح: & محح: & late \\
\hline $11: 11$ & ه & ! & early \\
\hline $11: 13$ & إحب; & iاحبزه & early \\
\hline $11: 17$ & ANai? & Mal & Lee, Urmia \\
\hline $11: 18$ & حمص:ل| & seyāme & early \\
\hline $11: 18$ & ححى & حس & Urmia \\
\hline $11: 20$ & أمعـ:| & iم:ا גط Lلحم & Lee, Urmia \\
\hline $11: 21$ & ha & 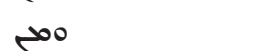 & Lee, Urmia \\
\hline $11: 23$ & زمسار & ح:0مسا & late \\
\hline $11: 23$ & ح:0مسه & حزممسا & early \\
\hline $11: 32$ & 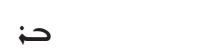 & وم & early \\
\hline $11: 41$ & ميرا & مسما رحبّ ح: & early \\
\hline $11: 42$ & مخله loa & مخهم & early \\
\hline $11: 46$ & مهاختما & no seyāme & early \\
\hline $12: 1$ & مممى & 9ممى & Lee, Urmia \\
\hline $12: 1$ & هله & , & early \\
\hline $12: 1$ & جنم loa & & early \\
\hline $12: 1$ & مب0ح000 & קحت:000. & Lee, Urmia \\
\hline $12: 1$ & حم/0ه1 & גa \a/ & Lee, Urmia \\
\hline $12: 12$ & محسا & by error twice & - \\
\hline 12:13 (L 12:14) & أزمسا & مصهן & early \\
\hline 12:14 (L 12:15) & וl" וla & مب גط וلحو & early \\
\hline 12:17 (L 12:18) & حمaحهماس & 0حمملمهماس & early \\
\hline 12:17 (L 12:18) & & iا & early \\
\hline 12:17 (L 12:18) & مذر & لخغ & early \\
\hline 12:19 (L 12:20) & وحتس & وحس & Lee, Urmia \\
\hline 12:19 (L 12:20) & $M, i$ & $W_{i i}$ & Lee, Urmia \\
\hline 12:21 (L 12:22) & ححبא & ححبr 000 & early \\
\hline 12:24 (L 12:25) & محقهـ & حقهم & early \\
\hline 12:24 (L 12:25) & متهول & مصت: & early \\
\hline 12:24 (L 12:25) & مسلا & مسلا حمنحا & early \\
\hline 12:31 (L 12:32) & أنسا & קحتץ أسما & early \\
\hline 12:32 (L 12:33) & حصدهן & صرحتّ00 & Lee, Urmia \\
\hline 12:40 (L 12:41) & 09, & •وحه ,حهحه & Lee, Urmia \\
\hline $13: 1$ & مصتهها & ممبحترا مصخهه| & late \\
\hline
\end{tabular}




\begin{tabular}{|c|c|c|c|}
\hline Place & Mosul & Leiden/7a1 & $\begin{array}{l}\text { Ms support } \\
\text { for Mosul }\end{array}$ \\
\hline $13: 2$ & مهمت & "بمس" & early \\
\hline $13: 6$ & حدדم, & حلهor. & Lee, Urmia \\
\hline $13: 7$ & סممه & مo & Lee, Urmia \\
\hline $13: 7$ & حה גی| & ה|ה & Lee, Urmia \\
\hline 13:8 & محتلا & om & Lee, Urmia \\
\hline $13: 8$ & •ز لر محتحسا & محتحدا محترل & Lee, Urmia \\
\hline 13:9 & 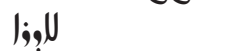 & seyāme & early \\
\hline $13: 10$ & So & oمس loa & Urmia \\
\hline \multirow[t]{2}{*}{$13: 11$} & 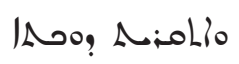 & مامنت ممدة & Lee, Urmia \\
\hline & & INoog! & \\
\hline $13: 13$ & Male & حمهد & Lee, Urmia \\
\hline $13: 13$ & : & loa isio & Lee, Urmia \\
\hline $14: 1$ & ومتما & no seyāme & early \\
\hline $14: 3$ & $a>$ & حه حب0م & Lee, Urmia \\
\hline $14: 11$ & مهلم & مهلمه & early \\
\hline $14: 11$ & ومب & مأمن: بومب & early \\
\hline $14: 11$ & مـ:ا & م:0 & Lee, Urmia \\
\hline $14: 15$ & لمصم:C|| & seyāme & early \\
\hline $14: 16$ & $i$ & حلرا & late \\
\hline $15: 2$ & محه|a & لمحها| & Urmia \\
\hline $15: 6$ & محتهوـ & مححتهو & late \\
\hline $15: 13$ & noiN & م & late \\
\hline $15: 16$ & ومسي & "محمحمى & late \\
\hline $15: 16$ & محختمر & مذام, & late \\
\hline $15: 17$ & أمتشم & jocant & late \\
\hline $15: 21$ & ممحسم & مممعمى & late \\
\hline $15: 22$ & ạم & aفl & Lee, Urmia \\
\hline $15: 22$ & حمهof & حمهلا & early \\
\hline $15: 29$ & גas:as & 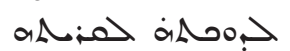 & early \\
\hline $15: 29$ & ومملحا & بمب| مهمهلحا & late \\
\hline $15: 29$ & Afato & Shaio & late \\
\hline 16:1 & لمحها| & لمحه|a & late \\
\hline 16:1 & م:م:ح & مم:حه & late \\
\hline 16:1 & محه|/2 & محم-aba & Lee, Urmia \\
\hline $16: 3$ & حسقس & مدبما حسقس & Lee, Urmia \\
\hline $16: 3$ & مب|3 & 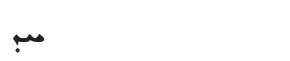 & Lee, Urmia \\
\hline
\end{tabular}




\begin{tabular}{|c|c|c|c|}
\hline Place & Mosul & Leiden/7a1 & $\begin{array}{l}\text { Ms support } \\
\text { for Mosul }\end{array}$ \\
\hline $16: 4$ & محها| ومن:ما & om & Lee, Urmia \\
\hline $16: 12$ & קح:2+2010 & 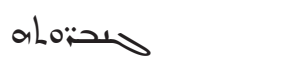 & early \\
\hline $16: 12$ & موبتا & no seyāme & Lee, Urmia \\
\hline $16: 13$ & محتهوص & حتهو & late \\
\hline $16: 16$ & ? & sos & Lee, Urmia \\
\hline 16:16 (L 16:17) & $\dot{a i g}\rangle^{\circ}$ & $\operatorname{ain} \operatorname{si}^{\circ}$ & Lee, Urmia \\
\hline $16: 17$ & حمغ:ل\} $&{\text { ملالم:نش }} &{\text { early }} \\
{\hline 16: 22} &{\text { Lام:حهر }} &{\text { مـامهم }} &{\text { late }} \\
{\hline 16: 25} &{\text { محقا }} &{\text { لمقة| }} &{\text { early }} \\
{\hline 16: 27} &{\text { |محهم| }} &{\text { |alo }} &{\text { early }} \\
{\hline 16: 29} &{\text { 9agegl }} &{\text { angeo, }} &{\text { late }} \\
{\hline 16: 30} &{\text { no, L }} &{\text { no,to }} &{\text { late }} \\
{\hline 16: 31} &{\text { من:ما }} &{\text { (من;مار }} &{\text { late }} \\
{\hline 16: 33} &{\text { ححمقةر }} &{\text { حمقةر }} &{\text { late }} \\
{\hline 16: 35} &{\text { ف:00مب2+1 }} &{\text { و:00مس }} &{\text { late }} \\
{\hline 16: 35} &{\text { مححتشه }} &{\text { حـمحتنيلy }} &{\text { late }} \\
{\hline 16: 36} &{\text { حنَ من: }} &{\text { حنب od من: }} &{\text { early }} \\
{\hline 16: 39} &{\text { 00, }} &{\text { مسفو }} &{\text { Lee, Urmia }} \\
{\hline 16: 39} &{\text { حمهزيل }} &{\text { }} &{\text { Lee, Urmia }} \\
{\hline 17: 1} &{\text { i }} &{\text { (Dio }} &{\text { late }} \\
{\hline 17: 2} &{\text { محص: }} &{\text { محص: مله" بمن:ا }} &{\text { late }} \\
{\hline 17: 4} &{\text { wi? }} &{\text { aصl أفن: منما انى }} &{\text { late }} \\
{\hline 17: 5} &{\text { مخفع }} &{\text { أفحا ومخفع }} &{\text { early }} \\
{\hline 17: 7} &{\text { م حهز حتا }} &{\text { مب حمىز حلا }} &{\text { late }} \\
{\hline 17: 10} &{\text { ل }} &{\text { حبما حدهم }} &{\text { late }} \\
{\hline 17: 11} &{\text { حمحهماب }} &{\text { خلمخه|a }} &{\text { early }} \\
{\hline 17: 12} &{\text { ل }} &{\text { om }} &{\text { late }} \\
{\hline 17: 17} &{\text { مومم iv }} &{\text { 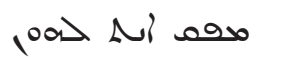 }} &{\text { late }} \\
{\hline 17: 18} &{\text { }} &{\text { بومب ححبץ }} &{\text { late }} \\
{\hline 17: 18} &{\text { هخم }} &{\text { ح, هخم }} &{\text { late }} \\
{\hline 17: 19} &{\text { حمهزحه }} &{\text { لمه, حه }} &{\text { early }} \\
{\hline 17: 20} &{\text { الحما }} &{\text { וגם }} &{\text { early }} \\
{\hline 17: 21} &{\text { حب }} &{\text { om }} &{\text { late }} \\
{\hline 17: 24} &{\text { حلهم2 }} &{\text { om }} &{\text { late }} \\
{\hline 17: 25} &{\text { > }} &{\text { حص }} &{\text { late }} \\
$\hline
\end{tabular}




\begin{tabular}{|c|c|c|c|}
\hline Place & Mosul & Leiden/7a1 & $\begin{array}{l}\text { Ms support } \\
\text { for Mosul }\end{array}$ \\
\hline \multirow[t]{2}{*}{$18: 7$} & oأحم أهן & om & Lee, Urmia \\
\hline & لlo; & & \\
\hline 18:10 & סمسسود & atoo & Lee, Urmia \\
\hline $18: 10$ & منحهـا & منحهل oa or & Lee, Urmia \\
\hline $18: 13$ & محتها & محختها & early \\
\hline $18: 15$ & مب:ح:نا & ومبص: & early \\
\hline 19:10 & סحص: & סحص:0 & early \\
\hline $19: 13$ & ladi? & adi? & late \\
\hline $19: 17$ & astio & anslio & Lee, Urmia \\
\hline $20: 3$ & محقي مه| & محوقي| & Lee, Urmia \\
\hline $20: 4$ & loa sol & ool loa & late \\
\hline $20: 4$ & 促 & e?a & late \\
\hline \multirow[t]{5}{*}{$20: 4 / 5$} & حتس קلحت: lo00 & om & Lee, Urmia \\
\hline & مامح مزحا حمر & & \\
\hline & وحقلما & & \\
\hline & الحسب حن حسب & & \\
\hline & الحسمس بمץ & & \\
\hline 20:6 & קبح:| هح:| مب & קح:| سب קهح:| & Lee, Urmia \\
\hline 20:6 & söa & om & early \\
\hline $20: 6$ & لمسمب:س|| & لمسمب:هL|| & Lee, Urmia \\
\hline $20: 8$ & حمسهب:ش| & لمسمب:ه|| & Lee, Urmia \\
\hline $21: 4$ & Lio & ILI & no support \\
\hline $21: 5$ & تهخا & קحت:| تקحا & no support \\
\hline $21: 5$ & مخقص & of & early \\
\hline $21: 12$ & حازيدا & حازح & early \\
\hline $21: 16$ & ممشر & ممسر 0iمسب & early \\
\hline $21: 17$ & حص: & ل لحب0 & late \\
\hline $21: 17$ & loal & a loak & early \\
\hline $21: 17$ & مب & 200 & no support \\
\hline $21: 18$ & 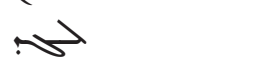 & خه & early \\
\hline $21: 21$ & هل أخدا & حبما للزخدا & late \\
\hline $21: 22$ & هa & مذ & late \\
\hline $21: 23$ & i & Wio & early \\
\hline $22: 2$ & وهمعه, & موهمع| & no support \\
\hline $22: 5$ & أمس:| & أمسن: & late \\
\hline $22: 5$ & "גط مذهم & حمدهم & Lee, Urmia \\
\hline
\end{tabular}




\begin{tabular}{|c|c|c|c|}
\hline Place & Mosul & Leiden/7a1 & $\begin{array}{l}\text { Ms support } \\
\text { for Mosul }\end{array}$ \\
\hline $22: 12$ & وفمبرب & وפمبس & late \\
\hline $22: 13$ & U & No & early \\
\hline $22: 14$ & ححمه & ?حشa" & late \\
\hline $22: 14$ & مامار & ماما حمسل & late \\
\hline $22: 18$ & גمهمة| & 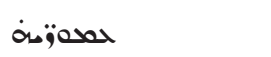 & late \\
\hline $23: 1$ & حمقته & a & Lee, Urmia \\
\hline 23:5 (L 23:4) & ممقرا & حممترا & late \\
\hline $23: 8$ & محتهصـ & حتهوى & Lee, Urmia \\
\hline 23:8 & Wiaso plaso & Wia pla & late \\
\hline 23:11 & | & حم:حه| & late \\
\hline $23: 18$ & حتهو & محتهם & early \\
\hline $23: 19$ & حتهو & محتهםص & early \\
\hline $23: 24$ & "حרגa & وملحتر ححله & late \\
\hline $23: 25$ & "انس & 9ושר 9 & late \\
\hline $23: 26$ & sọ & क्व & Lee, Urmia \\
\hline $23: 32$ & ${ }^{2}, 0000$ & 100010 & late \\
\hline $24: 5$ & م & 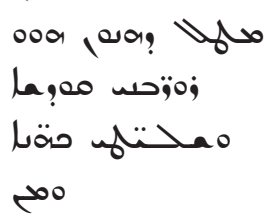 & late \\
\hline $24: 19$ & مستشت0ر & مسسم| & late \\
\hline $24: 19$ & حلحم 009 & لحم & late \\
\hline 24:19 & لحم:لط" & Wieni? & Urmia \\
\hline $24: 24$ & محتهو & حتهو & late \\
\hline $25: 1$ & a:90 & a:Dio & early \\
\hline $25: 1$ & 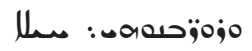 & مز0زحس مـلال & Lee, Urmia \\
\hline 25:1 (L 24:31) & حتهوـ & محتهوـ & Lee, Urmia \\
\hline 25:1 (L 24:31) & تمس & סزمص & Lee, Urmia \\
\hline $25: 2$ & 9o0 & 9000 & late \\
\hline $25: 4$ & م & م) & late \\
\hline $25: 24$ & لاحسد & الحمد & late \\
\hline $25: 25$ & حسس & مسل & late \\
\hline $25: 26$ & خمهد| & مهه| & late \\
\hline $25: 27$ & لاحد & الحد & late \\
\hline $25: 28$ & حهد & ;A & late \\
\hline $25: 29$ & حن:حس & ה:حس & late \\
\hline
\end{tabular}




\begin{tabular}{|c|c|c|c|}
\hline Place & Mosul & Leiden/7a1 & $\begin{array}{l}\text { Ms support } \\
\text { for Mosul }\end{array}$ \\
\hline $25: 30+31$ & text & om & Lee, Urmia \\
\hline $26: 1$ & فحخت & no seyāme & early \\
\hline $26: 4$ & $a>00 a$ & 000 & Lee, Urmia \\
\hline $26: 6$ & 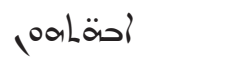 & احقةمهم & early \\
\hline $26: 7$ & קיב: & קיحتי & late \\
\hline $26: 8$ & مخدم, & محد>1001 & early \\
\hline $26: 8$ & ممب:aل & معبول & late \\
\hline $26: 9$ & حتّا & o00 حتار & late \\
\hline $26: 11$ & حتاز & حتهوـ & late \\
\hline 26:13-27 end & & & om Lee, Urmia \\
\hline 26:16 (L 26:15) & ححتهو. & 0ححتهو. & no support \\
\hline $26: 17$ & خهiحا & om & no support \\
\hline $26: 17$ & حهمال2 & مهر & no support \\
\hline $26: 24$ & ol דaمeil & Wiosano & no support \\
\hline $26: 28$ & مل" & Moso & early \\
\hline $26: 29$ & ححتبـا/ حتـ| & no seyāme & early \\
\hline $26: 30$ & محسحتهسا & حسح:مسا & no support \\
\hline $26: 30$ & م) & م & no support \\
\hline $26: 32$ & Noi? & oloto & early \\
\hline $26: 32$ & فحما محها & فحه , 9aحها & early \\
\hline $27: 1$ & حن:ما حنمار & منما حنما & no support \\
\hline $27: 3$ & 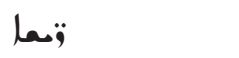 & مä & early \\
\hline $27: 6$ & קטح:| & קح:| & early \\
\hline $27: 11$ & م & بم & no support \\
\hline $27: 16$ & وحت مع:مل & Wieni? & no support \\
\hline $27: 16$ & خ:مححار & ح:0محار & no support \\
\hline $27: 24$ & 1000 & loa0 & early \\
\hline $27: 24$ & أه مسسا & مسار أه مسسا & no support \\
\hline $27: 25$ & بحمهزما & حمهزما & early \\
\hline $27: 27$ & وحص:مها & no seyāme & no support \\
\hline $27: 32$ & هح:l oa & קح:l loa & early \\
\hline $28: 1$ & مزمزحسا3 & مزةزحلا ومحصا & $7 \mathrm{a} 1$ \\
\hline $28: 4$ & حس1 & om & early \\
\hline 28:6 & 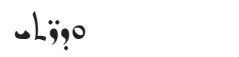 & no seyāme & no support \\
\hline $28: 7$ & حمح: & خمهن: & early \\
\hline $28: 7$ & أه بعمسا & أب عمسا & early \\
\hline
\end{tabular}




\begin{tabular}{|c|c|c|c|}
\hline Place & Mosul & Leiden/7a1 & $\begin{array}{l}\text { Ms support } \\
\text { for Mosul }\end{array}$ \\
\hline \multirow[t]{2}{*}{$28: 7$} & أومعب, حمحها & om & no support \\
\hline & a da & & \\
\hline $28: 9$ & حتحسم00م & حiحسهر & early \\
\hline $28: 11$ & |محمه|A| & |مهمقش/| & early \\
\hline $28: 15$ & INoge & INoo! & late \\
\hline $28: 17$ & U & No & early \\
\hline $28: 21$ & ححتبـ/|2 & 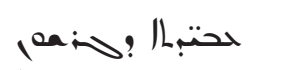 & Lee, Urmia \\
\hline & & l: & \\
\hline 28:21 & (גדגم & رحمد & early \\
\hline 29:1 & oa LNمه & مסصه حN, & late \\
\hline $29: 2$ & مش" & סטר & late \\
\hline $29: 4$ & elilo & مام & late \\
\hline $29: 7$ & مهزيديا & مه;بهما & معزنـ 7a1 \\
\hline $29: 7$ & ماملحم: & محري & no support \\
\hline $29: 9$ & مa & صهذم & Lee, Urmia \\
\hline \multirow[t]{2}{*}{ 29:11 } & مهصم|| & مخهمLا Wio & late \\
\hline & & aخه & \\
\hline $29: 16$ & 0خب س山 & مسب حر & early \\
\hline $29: 20$ & סحنy & مح:حه & early \\
\hline $29: 21$ & منهقر & no seyāme & Lee, Urmia \\
\hline $29: 21$ & وحتن/| & no seyāme & Lee, Urmia \\
\hline $29: 21$ & סעس حت صم:نط & مس حت & early \\
\hline $29: 24$ & סטר" & محذ1001 קهد:| & Lee, Urmia \\
\hline $29: 26$ & حمخهماa & حمخها| & late \\
\hline $29: 28$ & حمسحما| لحه| & حمتحه, هخر & early \\
\hline $29: 30$ & محخة & مخة & early \\
\hline $29: 30$ & 010:010:0 & seyāme & early \\
\hline $29: 30$ & مط & محة & late \\
\hline $29: 30$ & مون: & ومون; & Urmia \\
\hline
\end{tabular}

\section{Chronicles}

\begin{tabular}{|c|c|c|}
\hline 2:4 (L 2:3) & حمقر & محمقر \\
\hline 2:4 (L 2:3) & الحه, & וله, ححم, \\
\hline 2:4 (L 2:3) & ois & is \\
\hline
\end{tabular}




\begin{tabular}{|c|c|c|c|}
\hline Place & Mosul & Leiden/7a1 & $\begin{array}{l}\text { Ms support } \\
\text { for Mosul }\end{array}$ \\
\hline 2:5 (L 2:4) & 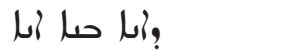 & 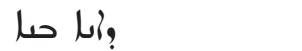 & Lee, Urmia \\
\hline \multirow[t]{4}{*}{ 2:7 (L 2:6) } & محمهول مسما & محمامار محسما & late \\
\hline & o: & محف:لال محاز & \\
\hline & Lay & 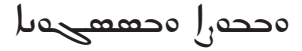 & \\
\hline & محهحل| مححهر| & | & \\
\hline 2:7 (L 2:6) & u!o & & Lee, Urmia \\
\hline 2:8 (L 2:7) & مومله:ما & no seyāme & early \\
\hline 2:14 (L 2:13) & oa ILNi ا & حi: loa ILNi & early \\
\hline 2:14 (L 2:13) & soshi? & soabi? & late \\
\hline 2:14 (L 2:13) & مخ محتمحس & حمر محتمحس & late \\
\hline 2:14 (L 2:13) & مسحتمه09. & 0حم محتمه09. & early \\
\hline 2:18 (L 2:17) & مخمهم, محص| & محلم| aحمه & late \\
\hline $3: 2$ & حملحم|a & 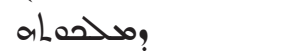 & early \\
\hline $3: 3$ & حـ| بِه:ما & حله ومه:ما & early \\
\hline $3: 5$ & حاز̈ا بومهتما & حمتتما بومهزما & early \\
\hline \multirow[t]{2}{*}{$3: 8$} & مولهa أمتر & om & early \\
\hline & حهi:م & & \\
\hline $3: 12$ & محول1 & 0000 & Lee, Urmia \\
\hline $3: 12$ & موحما & وخما & early \\
\hline $3: 14$ & ف:0مد| & همزم/1 & early \\
\hline \multirow[t]{2}{*}{$4: 4$} & لمحنحا ... & حمسما ... & early \\
\hline & حدمبا & لمحنحا & \\
\hline $4: 5$ & סקحמם & onoro & Urmia \\
\hline $4: 5$ & 000 & oag & late \\
\hline $4: 6$ & حقبا & حقار وسما & late \\
\hline $4: 9$ & لمسل & 9سما 9 9 & early \\
\hline $5: 1$ & סحسم & متص & late \\
\hline $5: 1$ & ححى & حـ & Urmia \\
\hline $5: 6$ & Wien? & om & early \\
\hline \multirow[t]{3}{*}{$5: 6$} & حتا ولا مهمتت & حتا هـامزا ول & Urmia, but \\
\hline & 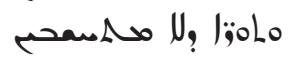 & مهلمب No & مهلمسر \\
\hline & & مهمسمحم & \\
\hline $5: 9$ & مقها & مقهمة & early \\
\hline $5: 10$ & UR & i Ui & early \\
\hline $6: 12$ & مذهم مقaم| & مقaم| مذهم & early \\
\hline $6: 12$ & ل لممسا & له| ممسا & Urmia \\
\hline
\end{tabular}




\begin{tabular}{|c|c|c|c|}
\hline Place & Mosul & Leiden/7a1 & $\begin{array}{l}\text { Ms support } \\
\text { for Mosul }\end{array}$ \\
\hline $6: 14$ & مه:| & مه:ما & Lee, Urmia \\
\hline $6: 16$ & حمهمما & حمة مس & late \\
\hline $6: 18$ & ${ }^{1}$ & par & $7 \mathrm{a} 1$ \\
\hline $6: 18$ & ${ }^{2} \boldsymbol{J}$ & UR & early \\
\hline $6: 19$ & الحه| & الحם & late \\
\hline $6: 20$ & ب! & ن & early \\
\hline $6: 20$ & مخممس لمس" & لممعس حمل| & early \\
\hline & $\mathrm{LO}_{3}$ & $a b\rangle_{3}$ & \\
\hline $6: 22$ & مهم| & seyāme & no support \\
\hline $6: 23$ & aldor, & palols, & late \\
\hline $6: 24$ & حخبحصه & حدجحقا & late \\
\hline $6: 28$ & م م & مص & early \\
\hline $6: 28$ & مصلما & محملمتر & early \\
\hline $6: 30$ & palat, & seyāme & early \\
\hline $6: 30$ & oa Ni? & Ni, & early \\
\hline $6: 31$ & بحه & بمده, حر & early \\
\hline $6: 32$ & مب:ته| زتسمه| & no seyāme & early \\
\hline $6: 34$ & حهبحتهو. & حدب:ححتי00 & early \\
\hline $6: 34$ & 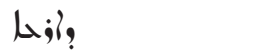 & حلز حل & early \\
\hline $6: 34$ & حمن:A| & من:م| & early \\
\hline $6: 35$ & ov & seyāme & early \\
\hline $6: 36$ & مب سل8ه & مهر M "سهi & Lee, Urmia \\
\hline $6: 38$ & 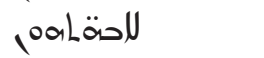 & ل الحهتم0م & early \\
\hline $6: 39$ & 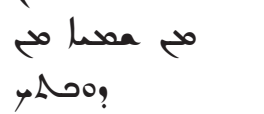 & 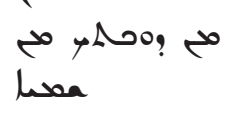 & late \\
\hline $6: 42$ & alorif & no seyāme & early \\
\hline $7: 5$ & |وحتش| & no seyāme & Lee, Urmia \\
\hline $7: 5$ & مسبا & مسباه & Urmia \\
\hline $7: 6$ & 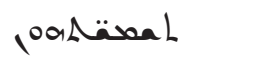 & no seyāme & early \\
\hline $7: 7$ & ومبرן & 9in مبر & Lee, Urmia \\
\hline $7: 10$ & مح:صه & محزحه & Lee, Urmia \\
\hline $7: 12$ & 9.רتהه| & no seyāme & Lee, Urmia \\
\hline $7: 14$ & منوص:0م & مLALO & Lee, Urmia \\
\hline $7: 14$ & كرد & مرحه & early \\
\hline $7: 17$ & Tal ? & ial, oow & late \\
\hline
\end{tabular}




\begin{tabular}{|c|c|c|c|}
\hline Place & Mosul & Leiden/7a1 & $\begin{array}{l}\text { Ms support } \\
\text { for Mosul }\end{array}$ \\
\hline $7: 18$ & woojial & worial & early \\
\hline $7: 18$ & حصمزمصا & مهزمصا & Lee, Urmia \\
\hline $7: 18$ & مهزمير & مهلهما & late \\
\hline $7: 19$ & 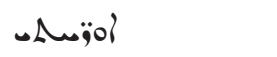 & (jol & late \\
\hline $7: 20$ & l,a & om & early \\
\hline $7: 22$ & $100 \lambda$ & أهم & late \\
\hline $8: 6$ & loa wig? & loa & Urmia \\
\hline $8: 6$ & סحصل" & محصحة & early \\
\hline 8:9 & صمهلهة & "? & late \\
\hline $8: 10$ & محتها & محتهرا & early \\
\hline $8: 10$ & مهلم & om & early \\
\hline 8:11 & i & loa & early \\
\hline $8: 11$ & U? & N & late \\
\hline $8: 13$ & ge pe & مل عم حهر & early \\
\hline $8: 14$ & pio & om & Lee, Urmia \\
\hline $8: 14$ & مهلت:0aLم & no seyāme & early \\
\hline 8:18 & بومال & حمها & early \\
\hline $9: 1$ & ?aحمه, & حمخمهم, & Lee, Urmia \\
\hline $9: 4$ & ممسر مممحتنهو. & مسمحا ومصمحقنهو. & early \\
\hline $9: 4$ & زمسا Lمح & Lمد ;ما & early \\
\hline $9: 6$ & متتره شتس & مسري حتس & early \\
\hline $9: 6$ & was & מם & early \\
\hline $9: 7$ & poi & مa & late \\
\hline $9: 9$ & مa & एक् & early \\
\hline $9: 11$ & ححمدם & وحمa & late \\
\hline $9: 12$ & حح: مب & حح: مب محبر & early \\
\hline $9: 12$ & a & om & Lee, Urmia \\
\hline $9: 13$ & حمس| & حمب| مبا & late \\
\hline $9: 16$ & مهنت & مص:م & early \\
\hline $9: 16$ & ححم & حص: & early \\
\hline $9: 16$ & ومبرا & !مص:ا & early \\
\hline $9: 24$ & ل & هماس وهدا & early \\
\hline $9: 24$ & متمل (by error) & مقممل & Urmia \\
\hline $9: 24$ & ! & م" & Urmia \\
\hline $9: 26$ & aخها & aحهi & late \\
\hline $9: 27$ & Wh Ai, & Wh, & early \\
\hline
\end{tabular}




\begin{tabular}{|c|c|c|c|}
\hline Place & Mosul & Leiden/7a1 & $\begin{array}{l}\text { Ms support } \\
\text { for Mosul }\end{array}$ \\
\hline $9: 30$ & Who & גל مهדه & Lee, Urmia \\
\hline $10: 3$ & حi: مخمهمן & حid بaمخمهן & early \\
\hline $10: 5$ & Niso & olio & early \\
\hline $10: 6$ & ofoa: loa & oأبّ: loa حم, & early \\
\hline 10:6 & لد & om & late \\
\hline $10: 7$ & ois: & & late \\
\hline 10:9 & حص1 & om & late \\
\hline $10: 14$ & أنا وبوا أنا & 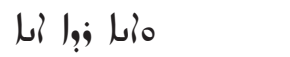 & late \\
\hline $10: 16$ & مبسu & aمu & Lee, Urmia \\
\hline $10: 16$ & مioم: & oiסنץ גa & late \\
\hline $10: 16$ & |lli & N Sio & early \\
\hline $10: 17$ & موبـحم & محت أمع:مل & Lee, Urmia \\
\hline $\begin{array}{l}11: 8 \\
\text { (L 1Rg 12:28) }\end{array}$ & هـخ & ختهل & early \\
\hline $\begin{array}{l}\text { 11:8 } \\
\text { (L 1Rg 12:28) }\end{array}$ & ميا & حمار & early \\
\hline $\begin{array}{l}\text { 11:9 } \\
\text { (L } 1 \operatorname{Rg} 12: 29)\end{array}$ & حـ & ححـ & Urmia (11:16) \\
\hline $\begin{array}{l}11: 10 \\
(L-1 \operatorname{Rg} 12: 30)\end{array}$ & حل & حهلا مب & late \\
\hline $\begin{array}{l}\text { 11:11 } \\
\text { (L } 1 \operatorname{Rg} 14: 1)\end{array}$ & La & ia & late \\
\hline $\begin{array}{l}\text { 11:14 } \\
\text { (L 1Rg 14:6) }\end{array}$ & حلص & حص & late \\
\hline $\begin{array}{l}11: 16 \\
\text { (L 1Rg 14:8) }\end{array}$ & Noso & âsono & $\begin{array}{l}\text { Lee, Urmia } \\
(11: 24)\end{array}$ \\
\hline $12: 14$ & لمحدمه & حمهحده & Urmia \\
\hline $13: 3$ & حختمدا & קحت| ححتمدا & late \\
\hline $13: 4$ & $\infty$ & ha & early \\
\hline $13: 5$ & ومخسا & 9هلما & early \\
\hline $13: 7$ & 9aح: & 9aح? loa & early \\
\hline $13: 8$ & $\mu$ & seyāme & Lee, Urmia \\
\hline 13:9 & مصط" فم & مط" فم & late \\
\hline $13: 11$ & alög & L L & early \\
\hline $13: 18$ & مسما & مس:ما oa & late \\
\hline $13: 19$ & مئم & 10:90 & early \\
\hline $13: 22$ & 9 & 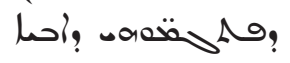 & early \\
\hline $13: 22$ & la & soa & late \\
\hline
\end{tabular}




\begin{tabular}{|c|c|c|c|}
\hline Place & Mosul & Leiden/7a1 & $\begin{array}{l}\text { Ms support } \\
\text { for Mosul }\end{array}$ \\
\hline 14:1 (L 13:23) & حمخهماa & حمحصهLا & late \\
\hline 14:1 (L 13:23) & مازمـا & no seyāme & Lee, Urmia \\
\hline 14:2 (L 14:1) & مaمن: & 0ومجى: & late \\
\hline 14:6 (L 14:5) & asa & poosal & early \\
\hline 14:8 (L 14:7) & متهو & مص:| & early \\
\hline 14:11 (L 14:10) & حبزع 2 & om & early \\
\hline 14:11 (L 14:10) & الحه, & الحa| & early \\
\hline 14:11 (L 14:10) & مrodal & مeal & early \\
\hline 14:13 (L 14:12) & פ" مسسا & ولا مسي & Urmia \\
\hline 14:13 (L 14:12) & 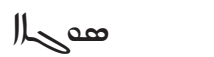 & م- & late \\
\hline $15: 11$ & وحتنا لمه:ما & حم:ما وحتنا & no support \\
\hline $15: 12$ & م محس & أiمه & Lee, Urmia \\
\hline $15: 14$ & owa & ilose & Lee, Urmia \\
\hline $15: 14$ & محم:ن| & حم:تII & early \\
\hline $15: 15$ & مدا, 200 & مط" & late \\
\hline $15: 15$ & pasoant & مامهمتهر & early \\
\hline 16:1 & Nao & مa متت & late \\
\hline $16: 4$ & ختحس متلا & خخمزحس مسلا & late \\
\hline 16:6 & حـ & وحس & Urmia \\
\hline 16:6 & مهمد & مهمحه & late \\
\hline 16:6 & محمتما & محلمتهصن & Lee, Urmia \\
\hline $16: 10$ & La Hoo & La La lo & late \\
\hline $16: 11$ & la & jora la & late \\
\hline \multirow[t]{2}{*}{ 16:12 } & a:Dlio & & early \\
\hline & & تصهl & \\
\hline $16: 13$ & حمن:ad & حمحمزاaLa & early \\
\hline $17: 1$ & حمخصهاa & حمهصها| & Lee, Urmia \\
\hline $17: 7$ & مزحص & مخ:حس & early \\
\hline $17: 10$ & مهب:تص| & ومب:ت1/ & Lee, Urmia \\
\hline $17: 14$ & زمزحسا & مز0زمةا & early \\
\hline $17: 14$ & محممعم 009 & محمدمى & late \\
\hline $17: 16$ & קبحتי مسلا & متحهلا ومسلال & no support \\
\hline $17: 19$ & ف & om & Lee, Urmia \\
\hline $18: 3$ & مامم حمس & وحمس امم & early \\
\hline 18:5 & & o: & early \\
\hline 18:6 & منم/ل\ & 9a/W & early \\
\hline
\end{tabular}




\begin{tabular}{|c|c|c|c|}
\hline Place & Mosul & Leiden/7a1 & $\begin{array}{l}\text { Ms support } \\
\text { for Mosul }\end{array}$ \\
\hline $18: 7$ & Ui & SU & late \\
\hline 18:8 & حد & om & late \\
\hline 18:11 & 莸, & om & no support \\
\hline $18: 13$ & 2/all & ורם & late \\
\hline 18:16 & ومحب: & محب:ز & late \\
\hline 18:19 & 1+2 & أم: أنا & Lee, Urmia \\
\hline $18: 21$ & aloi a a & مiob: גa من:ا & late \\
\hline $18: 21$ & ${ }^{2} a$ & om & late \\
\hline $18: 21$ & 9) & 910 & early \\
\hline $18: 21$ & $3 a$ & om & Lee, Urmia \\
\hline $18: 28$ & lgoos! & 9حل مa0, & late \\
\hline $18: 32$ & ! & ! & early \\
\hline 18:33 & ه:ما & 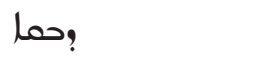 & early \\
\hline $19: 4$ & Lة" & paläا? & late \\
\hline 19:10 & סטי & م" & late \\
\hline 19:10 & learo & lea & early \\
\hline 19:11 & la & 100 & late \\
\hline 19:11 & مل" مبرן & محل مب:م & early \\
\hline $20: 2$ & ס & ספעh & early \\
\hline $20: 2$ & la & 100 & late \\
\hline $20: 3$ & ? & irli & early \\
\hline $20: 6$ & Ni Nio Nio & مخ Nio & early \\
\hline $20: 6$ & 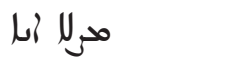 & ممرحلا & Lee, Urmia \\
\hline $20: 7$ & مبر & مخ مبرا & late \\
\hline $20: 9$ & مصص| & "ومصط" & late \\
\hline 20:9 & 2/Lلo & om & early \\
\hline 20:11 & rtolin & ILoLis & early \\
\hline $20: 15$ & ther tha & La the & early \\
\hline 20:16 (L 20:17) & مب0 & sor & late \\
\hline $20: 18$ & סעים: & 0 & early \\
\hline $20: 20$ & anda & & early \\
\hline $20: 25$ & مزّما & פوפصما & late \\
\hline 20:26 (L 20:25) & حه; & مح حه; & early \\
\hline $20: 26$ & الحما & 10001 & late \\
\hline $20: 26$ & La La & La loo & early \\
\hline $20: 29$ & Wa & aمه & Lee, Urmia \\
\hline
\end{tabular}




\begin{tabular}{|c|c|c|c|}
\hline Place & Mosul & Leiden/7a1 & $\begin{array}{l}\text { Ms support } \\
\text { for Mosul }\end{array}$ \\
\hline $20: 30$ & fanoos? & 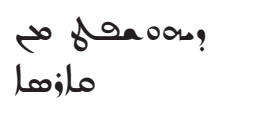 & Lee, Urmia \\
\hline $20: 30$ & من:ما مح مبت000 & 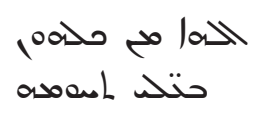 & Lee, Urmia \\
\hline $20: 31$ & أمخر مa000 & 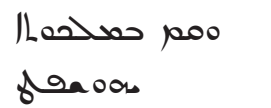 & Lee, Urmia \\
\hline $20: 31$ & ${ }^{2}$ onod & om & late \\
\hline $21: 2$ & loa ㄱ? & 00a Ni & early \\
\hline 21:9 & منح & منحه & early \\
\hline $21: 14$ & مسمتب & محمتب & Lee, Urmia \\
\hline $21: 19$ & ححب: & ححب0 & late \\
\hline $21: 20$ & حمن:A| & حم:iN & early \\
\hline $22: 1$ & l;ar & om & early \\
\hline $22: 1$ & مص:م|| ومه:هل & |مaت:A| & early \\
\hline $22: 2$ & loa & حi: حهن: after & late \\
\hline $22: 2$ & boas & dano & early \\
\hline $22: 6$ & حامرز حسل2 & 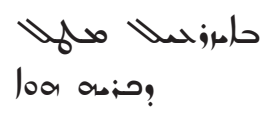 & late \\
\hline $22: 8$ & 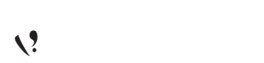 & loo $?$ & Lee, Urmia \\
\hline $23: 1$ & حمب| & محمس| & early \\
\hline 23:2 [L 23:1] & مذا, ad حم & aحم مها001 & early \\
\hline $23: 2$ & حمهمت & no seyāme & Lee, Urmia \\
\hline $23: 2$ & סمصمه & مصلص & early \\
\hline $23: 3$ & حمهمته| & مهم| & early \\
\hline $23: 4$ & 管 & no seyāme & early \\
\hline $23: 8$ & موح: & مبوح:0 & late \\
\hline $23: 10$ & حمب:حسا & مخحب:حسا & early \\
\hline $23: 11$ & مسهوزן & مسهوן & late \\
\hline $23: 12$ & 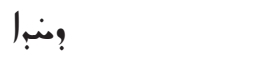 & פחبץ & late \\
\hline $23: 14$ & لت:حس & ح:مزحس & early \\
\hline $23: 16$ & حمهمه| & مهمى| & early \\
\hline $23: 16$ & محه & مط" & early \\
\hline $23: 19$ & U, & No & late \\
\hline $24: 1$ & متت & loa a متت & early \\
\hline $24: 1$ & ona & مaما & Lee, Urmia \\
\hline $24: 5$ & مat & om & late \\
\hline
\end{tabular}




\begin{tabular}{|c|c|c|c|}
\hline Place & Mosul & Leiden/7a1 & $\begin{array}{l}\text { Ms support } \\
\text { for Mosul }\end{array}$ \\
\hline $24: 17$ & 0م- & סעי & Lee, Urmia \\
\hline $24: 22$ & Lof & no seyāme & early \\
\hline $24: 24$ & أمخده & أمخده & Lee, Urmia \\
\hline 24:24 (L 24:25) & 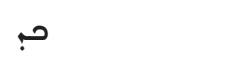 & مص: & late \\
\hline $24: 25$ & 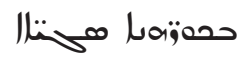 & no seyāme & Lee, Urmia \\
\hline $24: 25$ & حم:ند| & حم:نه & early \\
\hline $24: 26$ & & & early \\
\hline $25: 8$ & منحا & منحا زمزحا & early \\
\hline $25: 11$ & iمه, & & late \\
\hline $25: 12$ & acio & Nio & early \\
\hline $25: 12$ & ماقر & no seyāme & Lee, Urmia \\
\hline $25: 16$ & حمحق| & no seyāme & early \\
\hline $25: 17$ & أمهربا محلما & محلا iمعربا & early \\
\hline $25: 19$ & محذه & موحه & late \\
\hline 25:20 (L 25:21) & مأمعرا مهلما & om & early \\
\hline $25: 23$ & مبمها & لمبما & late \\
\hline $26: 3$ & L,er & after aتم & Lee, Urmia \\
\hline $26: 3$ & الحمما & مبر & early \\
\hline $26: 16$ & Anillit & a Loa AailLl & late \\
\hline $26: 20$ & ممنما بمة| & محذهمر صةّا & Lee, Urmia \\
\hline $26: 21$ & ومب:Le & ل & Lee, Urmia \\
\hline $26: 23$ & محهز| & no seyāme & Lee, Urmia \\
\hline $27: 2$ & N & U? & Lee, Urmia \\
\hline $27: 5$ & مهنحه & ومـ:حه & Lee, Urmia \\
\hline $27: 7$ & jog & jea la & early \\
\hline 27:8 (L 27:9) & حم:ن| & حم:ad & Lee \\
\hline $28: 1$ & أمخج & ممر حمخهما| & late \\
\hline $28: 9$ & لحمه & حما & late \\
\hline $28: 9$ & & paläا? & late \\
\hline $28: 10$ & 2910 & 9i & early \\
\hline $28: 13$ & 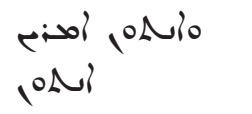 & 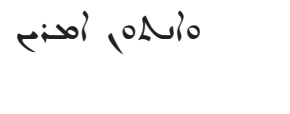 & late \\
\hline 28:14 (L 28:15) & حمحد| محة & محة محسد| & late \\
\hline 28:15 (L 28:22) & 90010 & 090010 & early \\
\hline $28: 16$ & a loa & مب:ز & early \\
\hline
\end{tabular}




\begin{tabular}{|c|c|c|c|}
\hline Place & Mosul & Leiden/7a1 & $\begin{array}{l}\text { Ms support } \\
\text { for Mosul }\end{array}$ \\
\hline $28: 16$ & حمد:0Lاa & حمالLا لمحب:aLoاa & late \\
\hline $28: 17$ & حصى & حبحـ & early \\
\hline $28: 19$ & ? & ? & early \\
\hline $28: 21$ & | & وبه & early \\
\hline $28: 23$ & 000 & oa & early \\
\hline $28: 25$ & وحتا لحبرحس & مب:حتنا حموحس & Lee, Urmia \\
\hline $28: 26$ & la & pora la & late \\
\hline $28: 27$ & 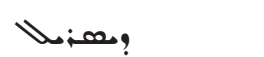 & l,0009.9 & early \\
\hline $29: 1$ & 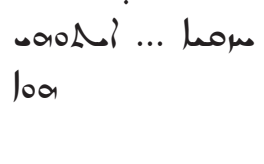 & 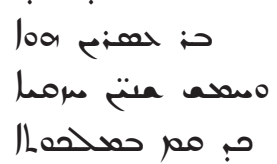 & early \\
\hline $29: 6$ & "ححب02 & محب.0 & Lee, Urmia \\
\hline $29: 6$ & مبحتم000 & مبحد0 & late \\
\hline $29: 7$ & ?م:0له & seyāme & late \\
\hline $29: 9$ & محتي & مستخ محتت & Lee, Urmia \\
\hline 29:9 & حمحم & حمحل| & early \\
\hline $29: 21$ & مةّل & no seyāme & early \\
\hline $29: 27$ & أح & أד أד & early \\
\hline $29: 31$ & oNi & onio & early \\
\hline $29: 33$ & 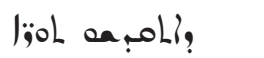 & 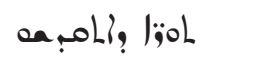 & no support \\
\hline $29: 35$ & 9io & 9i & early \\
\hline $29: 36$ & "م) محد & مهم ملد & early \\
\hline $30: 1$ & خم:ما & حمن:ما سمحه| & early \\
\hline $30: 2$ & & listio & Lee, Urmia \\
\hline $30: 2$ & 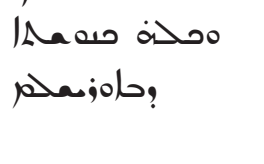 & 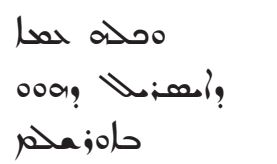 & Lee, Urmia \\
\hline $30: 3$ & illi & ooa angol? & late \\
\hline $30: 6$ & محهمبمال & حههمبرا & late \\
\hline $30: 6$ & y00010 & TOaso & late \\
\hline $30: 9$ & مبر & حمى & Lee, Urmia \\
\hline $30: 9$ & 200 & om & late \\
\hline $30: 10$ & ححنم 000 & ححنم & late \\
\hline 30:11 (L 30:10) & م-000000 & סمحسم: & early \\
\hline $30: 14$ & من:حه & وפمحتا حمنه & Lee, Urmia \\
\hline $30: 16$ & مةرا & ل ومةّا & early \\
\hline
\end{tabular}




\begin{tabular}{|c|c|c|c|}
\hline Place & Mosul & Leiden/7a1 & $\begin{array}{l}\text { Ms support } \\
\text { for Mosul }\end{array}$ \\
\hline $30: 17$ & סمسم & 0مسم 000 & early \\
\hline $30: 18$ & ويما & حوبرا & early \\
\hline $30: 18$ & حما مذه & مذه حما & early \\
\hline $30: 19$ & معوبم & la,000 & early \\
\hline $30: 21$ & סح" & om & early \\
\hline $30: 21$ & ممحسم & مممحسم & early \\
\hline $30: 22$ & حهمحتش| & |محتشA| & early \\
\hline $31: 1$ & ملهر & aحمه & early \\
\hline $31: 2$ & مهلم: & no seyāme & early \\
\hline $31: 5$ & 'اסצע & סעy & Lee, Urmia \\
\hline 31:6 & סمس م & مشרم & late \\
\hline $31: 10$ & & Doio & late \\
\hline $31: 13$ & وصسار & ومنسا & Lee, Urmia \\
\hline $31: 18$ & محصده & محصط & early \\
\hline $31: 20$ & oمari & موم: & late \\
\hline $32: 1$ & INa000 & La INacos & late \\
\hline $32: 4$ & & & early \\
\hline $32: 5$ & l̈̈a & no seyāme & no support \\
\hline $32: 7$ & li & illio & early \\
\hline $32: 7$ & حمى & ! بمحم & early \\
\hline $32: 9$ & مم حه; & هم حهز; & Lee, Urmia \\
\hline 32:9 & حزحمقر & خ:ح مما & early \\
\hline $32: 11$ & & مأסن: حصم & Lee, Urmia \\
\hline $32: 14$ & סمهים & مهه & late \\
\hline $32: 15$ & asoul & nal a محسه & Lee, Urmia \\
\hline $32: 16$ & Whing & om & Lee, Urmia \\
\hline $32: 17$ & 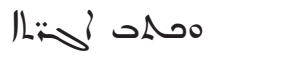 & نיקتLا صـح & Lee, Urmia \\
\hline $32: 17$ & لحمىن: & لمسمب:0 & Lee, Urmia \\
\hline $32: 20$ & حملا 93_oaloa & منما حملا & late \\
\hline $32: 22$ & asous & pasoont & late \\
\hline $32: 23$ & حمقخا مذهم, & مخد0/, حمقتر & late \\
\hline $32: 25$ & Laigon & om & Lee, Urmia \\
\hline $32: 25$ & 9 وم:ما & om & Lee, Urmia \\
\hline $32: 25$ & حس & פحس & Lee, Urmia \\
\hline
\end{tabular}




\begin{tabular}{|c|c|c|c|}
\hline Place & Mosul & Leiden/7a1 & $\begin{array}{l}\text { Ms support } \\
\text { for Mosul }\end{array}$ \\
\hline $32: 26$ & مهل" & ح:مها| ,وحه & Lee, Urmia \\
\hline $32: 26$ & l & ando; & early \\
\hline $32: 27$ & مخمتهب| & סحم:>ע|| & early \\
\hline $32: 27$ & تص & 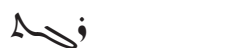 & late \\
\hline $32: 28$ & م,0ومسا & مهمسر & early \\
\hline $32: 30$ & خ & خلحما & early \\
\hline $32: 30$ & ?a) & גas:as & early \\
\hline $32: 32$ & 0حم9:| & 0أ9 حم9:1 & Urmia \\
\hline $33: 1$ & حمخهماa & حمحها| & Lee, Urmia \\
\hline $33: 2$ & ? & "حمـ: & Lee, Urmia \\
\hline $33: 3$ & 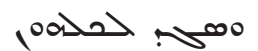 & 0حمد00, & late \\
\hline $33: 7$ & بحامزمحهر & حامزملهر & Urmia \\
\hline $33: 8$ & محمتمس محبتس & مخمتمحهو & late \\
\hline & & محب:تهو & \\
\hline 33:11 & مه:ما حلدهم & حلح00, من:ما & early \\
\hline $33: 13$ & حمخحماa & خملحماa & Lee, Urmia \\
\hline $33: 14$ & محنحرا & مسنحا & early \\
\hline $33: 15$ & 0رخقا & مخد خقار & early \\
\hline $33: 15$ & حس| & حسגם & early \\
\hline $33: 16$ & läolo & IAgolo & early \\
\hline $33: 17$ & محخة|l & גل هحةLا & Lee, Urmia \\
\hline $33: 18$ & الحم|1 & aall & late \\
\hline $33: 18$ & حممه & حممار & no support \\
\hline $33: 19$ & & wolaigo & late \\
\hline $33: 19$ & محب: & 0و حح: & late \\
\hline $33: 21$ & حن: حمَ:م & ح: حمتزم loa & early \\
\hline $34: 1$ & ح: Lمبا & ح: Lميا loa & late \\
\hline $34: 4$ & وحصبم & وححبא & Lee, Urmia \\
\hline $34: 5$ & of & s. & late \\
\hline $34: 5$ & م:0010 & مـ & Lee, Urmia \\
\hline $34: 6$ & محس & 0وحـ & late \\
\hline $34: 9$ & "مده مع:ط\" & وحما مذه & late \\
\hline & & "Wil? & \\
\hline $34: 12$ & ححتب Lا & ححتبـLا & early \\
\hline $34: 17$ & م:مص & م.0دم >a & Lee, Urmia \\
\hline
\end{tabular}




\begin{tabular}{|c|c|c|c|}
\hline Place & Mosul & Leiden/7a1 & $\begin{array}{l}\text { Ms support } \\
\text { for Mosul }\end{array}$ \\
\hline $34: 18$ & 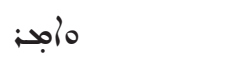 & aio: a a & Lee, Urmia \\
\hline $34: 26$ & مג山" محلم & محمحار & late \\
\hline $34: 28$ & محهزّ & محهزب & no support \\
\hline $34: 30$ & âl? & & early \\
\hline $34: 31$ & مهمته| & no seyāme & Urmia \\
\hline $34: 32$ & م00 مط & ممبر مل فخ & Lee, Urmia \\
\hline $34: 33$ & محص & م & late \\
\hline $34: 33$ & من:ا & om & early \\
\hline $35: 3$ & مام & Dol & Lee, Urmia \\
\hline $35: 5$ & حa) & seyāme & late \\
\hline $35: 5$ & مأمتحهم & •ونأمتصه & early \\
\hline $35: 6$ & סححب0ן & פטح:0 & late \\
\hline $35: 6$ & مeمال & أمتحهم & early \\
\hline $35: 8$ & مز0;0حس00ـ & 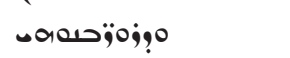 & late \\
\hline $35: 8$ & o:a:9o & a:a & Lee, Urmia \\
\hline $35: 8$ & حتا & om & late \\
\hline $35: 8$ & |̈̈0Lo & متتا & late \\
\hline $35: 11$ & 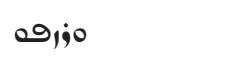 & o, & Lee, Urmia \\
\hline $35: 12$ & حمه:| وبمهما & حمحمما & late \\
\hline $35: 13$ & ا & أمصال & late \\
\hline $35: 13$ & محات:| محم:بول & 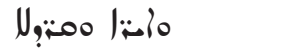 & early \\
\hline $35: 14$ & مهممب 000 & 00a 000 م00مي & Lee, Urmia \\
\hline $35: 15$ & همبمبا & ومبده & Lee, Urmia \\
\hline $35: 15$ & إما & seyāme & late \\
\hline $35: 16$ & همبرا & هos:ده & Urmia \\
\hline $35: 18$ & No & $\mathrm{N}$ & late \\
\hline $35: 21$ & ild & | & Lee, Urmia \\
\hline $35: 21$ & $\infty$ & مس م & $7 \mathrm{a} 1$ \\
\hline $35: 21$ & 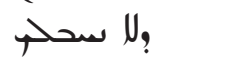 & ل ل سحخף & $7 \mathrm{a} 1$ \\
\hline $35: 23$ & סأْب: محلما & مأمب: محبها & Lee, Urmia \\
\hline $35: 27$ & la & om & early \\
\hline $36: 1$ & حمار & حما وجزخدا & late \\
\hline $36: 1$ & حمحهماه & حمخهما| & late \\
\hline $36: 2$ & حi: حهن:م & حن: المتّم loa & early \\
\hline $36: 2$ & loa & om & early \\
\hline
\end{tabular}




\begin{tabular}{|c|c|c|c|}
\hline Place & Mosul & Leiden/7a1 & $\begin{array}{l}\text { Ms support } \\
\text { for Mosul }\end{array}$ \\
\hline $36: 8$ & 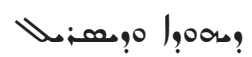 & & early \\
\hline $36: 9$ & ح: Lمنسم:| & ح: Lمسحم:ا loa & early \\
\hline $36: 10$ & مهحا & محها وححط" & early \\
\hline $36: 10$ & & 20 & late \\
\hline $36: 11$ & ح: حمن: & ح: حمتّم loa & early \\
\hline $36: 14$ & م" & om & early \\
\hline $36: 14$ & حامزمحهر & وحامزمحهر & Lee, Urmia \\
\hline $36: 15$ & 9م:ما & ? & late \\
\hline $36: 17$ & Ulo & U शे & early \\
\hline $36: 18$ & iحده & Woi & late \\
\hline $36: 19$ & حمهزته & aمةiه & Lee, Urmia \\
\hline $36: 19$ & محله & محل\ & early \\
\hline $36: 20$ & oمe & مأهم & early \\
\hline $36: 20$ & حصبت & ل حقبا & late \\
\hline $36: 23$ & وحس00 & وحص00, & Lee, Urmia \\
\hline
\end{tabular}

